\title{
Psicodinâmica do trabalho: da França ao Estado de Goiás: sua inserção na comunidade
}

Kátia Barbosa Macêdo. Pontifícia Universidade Católica de Goiás

Fábio Jesus Miranda. Pontifícia Universidade Católica de Goiás

\section{Resumo}

A clínica psicodinâmica do trabalho foi introduzida no Brasil na década de 1980. Propõe uma metodologia específica para a análise da mobilização subjetiva dos trabalhadores. Este estudo apresenta a inserção dessa abordagem no Brasil, especificamente em Goiás. Utilizou a análise documental do banco de dados da plataforma Sucupira - Capes, no período de 2007 a 2019. Os Resultados indicam: conclusão de 166 orientações; produção bibliográfica de 154 publicações e produção técnica com 254 apresentações em eventos. Duas categorias temáticas emergiram da análise dos dados: organização do trabalho e mobilização subjetiva do trabalhador (vivências de prazer-sofrimento e estratégias de enfrentamento), indicando convergência com a abordagem dejouriana. Temas com maior destaque foram: saúde mental; assédio moral; prazer e sofrimento no trabalhador. Foram atendidas organizações públicas, privadas e do terceiro setor. A produção encontra-se comprometida com: relações de trabalho emancipatórias e promoção da qualidade de vida no trabalho e saúde mental.

Palavras-chave: psicodinâmica; trabalho; saúde mental.

\begin{abstract}
Psychodynamics of work: from France to Goiás: its insertion into community. The psychodynamic clinic at work was introduced in Brazil in the 1980s. It proposes a specific methodology for the analysis of workers' subjective mobilization. This study presents the insertion of this approach in Brazil, specifically in Goiás. It used the documentary analysis of Sucupira - Capes platform database, from 2007 to 2019. Results indicate: completion of 166 guidelines; bibliographical production of 154 publications and technical production with 254 presentations at events. Two thematic categories emerged from the data analysis: work organization and subjective worker mobilization (pleasure-suffering experiences and coping strategies), indicating convergence with the Dejourian approach. The most prominent themes were: mental health; bullying; pleasure and suffering in the worker. Public, private and third sector organizations were served. The production is committed to: emancipatory working relationships and promotion of quality of life at work and mental health.
\end{abstract}

Keywords: psychodynamics; work; mental health.

\section{Resumen}

Psicodinámica del trabajo: de Francia hacia Goiás: su inserción en la comunidade. La clínica psicodinámica del trabajo se introdujo en Brasil en la década de 1980. Propone una metodología específica para el análisis de la movilización subjetiva de los trabajadores. Este estudio presenta la inserción de este enfoque en Brasil, específicamente en Goiás. Se utilizó el análisis documental de la base de datos de la plataforma Sucupira - Capes, de 2007 a 2019. Los resultados indican: la finalización de 166 directrices; Producción bibliográfica de 154 publicaciones y producción técnica con 254 presentaciones en eventos. Del análisis de datos surgieron dos categorías temáticas: organización del trabajo y movilización subjetiva de los trabajadores (experiencias de sufrimiento-placer y estrategias de afrontamiento), lo que indica la convergencia con el enfoque dejouriano. Los temas más destacados fueron: salud mental; intimidación placer y sufrimiento en el trabajador. Se atendió a organizaciones públicas, privadas y del tercer sector. La producción está comprometida con: relaciones laborales emancipadoras y promoción de la calidad de vida en el trabajo y la salud mental.

Palabras clave: psicodinámica; trabajo; salud mental. 


\section{Psicodinâmica, saúde e trabalho}

A saúde mental é um importante impulsionador dos resultados no mercado de trabalho e, portanto, afeta o crescimento econômico e o desenvolvimento futuro (Organisation for Economic Co-operation and Development [OECD], 2015). A preocupação com a saúde mental dos trabalhadores é tema analisado por organizações de renome mundial, como a OECD - Organization for Economic Co-operation and Development, WHO - World Health e ILO - International Labor Organization, conforme pode se perceber nos documentos emitidos por esses órgãos: (Houtman \& Kompier, 2011; International Labor Organization [ILO], 2000; OECD, 2012; 2015; World Health Organization [WHO], 2000) e planos de ação (WHO, 2013a; 2013b). Segundo informações da WHO (2000), o impacto de problemas de saúde mental no local de trabalho tem consequências graves não só para o indivíduo, mas, também, para a produtividade da empresa, em que se pese o impacto no desempenho do empregado, nas taxas de adoecimento, no absenteísmo, acidentes e rotatividade do pessoal.

As mudanças no mundo do trabalho, principalmente no que se refere à adoção de novas tecnologias e métodos gerenciais, têm refletindo sobre o viver, o adoecer e o morrer dos trabalhadores. Novas formas de adoecimento surgem em decorrência de estresse, fadiga física e mental e outras manifestações de sofrimento relacionadas ao trabalho (Araújo, Palma, \& Araújo, 2017). O aumento do número de suicídios de trabalhadores constitui em mais um indicador da pertinência de se abordar a saúde mental como fator primordial dos modelos de organização do trabalho e gestão nas organizações e sociedade.

Abordar saúde mental e trabalho pressupõe adotar uma visão interdisciplinar, incorporando contribuições advindas das ciências sociais, economia, medicina, psicologia, psicanálise, epidemiologia e ergonomia (Uchida, Lancman, \& Sznelwar, 2014). Isso se constitui para os pesquisadores um desafio de desenvolver abordagens teóricas e metodológicas que discutam as interações entre a organização do trabalho e a subjetividade dos trabalhadores. O Colóquio de Bonneval, organizado em 1946 por Henri Ey, visou discutir a relação entre loucura e trabalho. Contou com a participação de profissionais da psiquiatria, psicopatologia e psicanálise. Desse colóquio surgiram três diferentes posicionamentos doutrinários sobre a causalidade das doenças mentais: as teses da organogênese (Henri Ey); da psicogênese (Jacques Lacan) e da sociogênese (Lucien Bonnafé) da doença mental, conforme Molinier (2013). Essa discussão não chegou a um consenso nem à época tampouco atualmente, possivelmente pelo aspecto multifatorial da gênese da psicopatologia. Apesar disso, a necessidade de continuar abordando o tema levou ao surgimento das clínicas do trabalho.

As clínicas do trabalho possuem alguns pontos de convergências: interesse pela ação no trabalho; trabaIho esse entendido como atividade sustentada por um projeto de transformação do real e de construção de significados pessoais e sociais; defesa de uma teoria do sujeito e a abordagem do sofrimento e mal-estar no trabalho (Bendassolli \& Soboll, 2011). As clínicas do trabalho são: a psicodinâmica do trabalho; a clínica da atividade; a psicossociologia e a ergologia. No presente estudo, enfocaremos a psicodinâmica do trabalho que se desenvolveu a partir do Laboratório de Saúde e trabalho no Conservatoire National des Arts et Métiers - CNAM.

O CNAM, fundado em 10 de outubro de 1794, é uma instituição do tipo grande escola de ensino superior e pesquisa, operado pelo governo francês para a promoção da ciência e da indústria, que oferece cursos da graduação ao doutorado. Em 1966, Alain Wisner se tornou o diretor do Laboratório de Fisiologia do Trabalho do CNAM e inaugurou um dispositivo de ensino em tempo integral para qualificar sindicalistas e estudantes estrangeiros em ergonomia. (Sznelwar, 2006). Wisner acreditava que havia alternativas frente ao esgotamento físico e emocional do trabalho. Para ele havia muitas perdas econômicas que poderiam ser prevenidas se o projeto das máquinas e da produção fosse outro (Molinier, 2013).

Em 1990 foi fundado no CNAM o Laboratório de Psicologia do Trabalho, que em 2001 passou a se chamar Laboratório de Psicologia do Trabalho e da Ação e atualmente se denomina Grupo de Pesquisa em Psicanálise, saúde e trabalho, coordenado pelo Prof. Dr. Christophe Dejours. Após 2013, esse grupo iniciou um processo de transição do CNAM para a Université Paris Descartes 5, ligado ao Laboratoire Psychologie Clinique, Psychopathologie, Psychanalyse.

A psicodinâmica do trabalho é multidisciplinar. Desde sua constituição ela se pauta em diálogos com a ergonomia, psicanálise, sociologia do trabalho, psicopatologia, psicologia, medicina do trabalho, dentre outras. Desde sua concepção, a abordagem tinha como objetivo o estudo das relações entre saúde mental e trabalho. 
Inicialmente o enfoque era na psicopatologia do trabaIho, a ênfase era no adoecimento do trabalhador.

Na medida em que os estudos foram se desenvolvendo, Dejours $(1992,2004)$ constatou que os trabalhadores, mesmo em situações precárias e patogênicas de labor, nem sempre desenvolviam doenças mentais e que as pessoas que trabalhavam tendiam a estar em melhores condições psíquicas do que aquelas que não trabalhavam. A emergência desses aspectos levou a uma mudança de ênfase nos estudos, interessando-se mais em saber o que esses trabalhadores que não adoeciam faziam para manter sua saúde. Em virtude desse redirecionamento, a abordagem passou a pesquisar a mobilização subjetiva dos trabalhadores, utilizando para isso uma nova metodologia e denominação: Psicodinâmica do Trabalho - PDT, que tem como objeto de pesquisa a vida psíquica no trabalho, como foco no sofrimento psíquico e nas estratégias de enfrentamento utilizadas pelos trabalhadores para a superação e a transformação do trabalho em fonte de prazer.

A formação psicanalítica e em ergometria de Dejours influenciou o delineamento de um método que possibilitou ao pesquisador compreender a mobilização subjetiva do trabalhador em relação ao seu trabaIho. Várias das regras e recomendações da psicanálise são consideradas como parâmetros para uma postura adequada do pesquisador em PDT.

Conforme Macêdo e Heloani (2017):

Não é o pesquisador que adota a atitude de condução, ele não dá conselhos. O pesquisador permite que as pessoas descubram e comecem a pensar de outra maneira sua relação com o trabalho. [...] é isso o trabalho do pesquisador, a ação do pesquisador: catalisar, estimular, mobilizar a capacidade de pensar das pessoas que possuem a experiência. Perlaborar a experiência do trabaIho é o que até agora não era consciente, mas, no entanto, ela estava lá. É isso que nós chamamos de trabalho vivo. Então, é a perlaboração que permite a revelação do trabalho vivo. É esse o princípio desse coletivo (p. 499).

O que fica claro é que qualquer ação em PDT parte de um vínculo entre pesquisador e o coletivo de trabalhadores. Para uma visualização das etapas do método da PDT, a Figura 1 apresenta sua comparação com as etapas do processo analítico. As etapas propostas por Dejours (1992) são: a construção do estudo pela pré-pesquisa; a pesquisa (enquete) propriamente dita; a análise da demanda; a análise do material da pesquisa e a observação clínica; a interpretação; a validação e refutação. Elas são norteadoras para a construção do trabalho em clínica do trabalho, e devem analisar as peculiaridades de cada pesquisa para a definição do método.

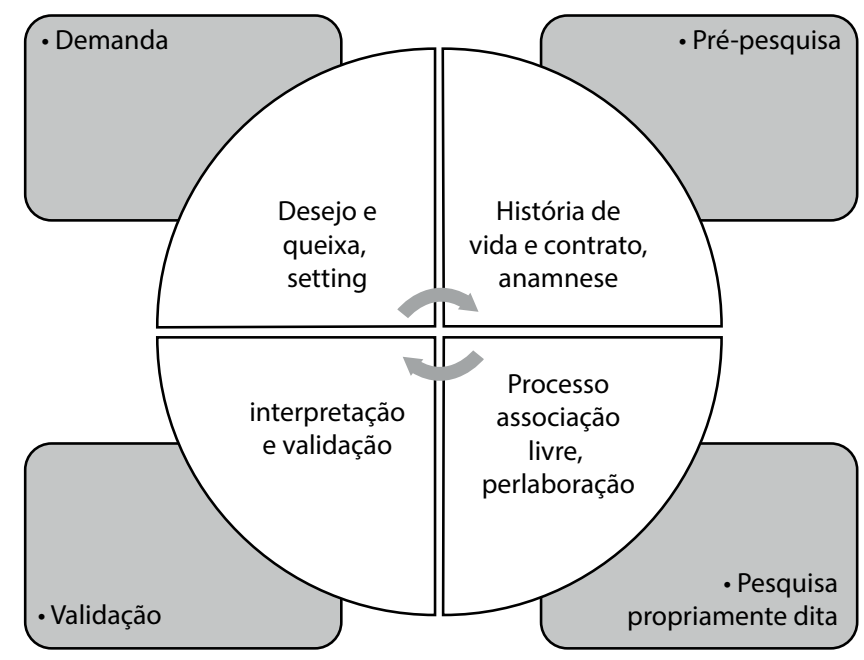

Figura 1. Representação Gráfica das Etapas do Processo Analítico e sua Correspondência com as Etapas do Método da PDT.

Fonte: Elaborada pelos autores.

Dada a importância do mundo do trabalho e a relação do trabalhador com sua atividade laboral, a Psicodinâmica do trabalho se expandiu para além dos limites de sua origem francesa. Conhecer como ela chegou ao Brasil e como ocorreu sua expansão, constitui o ponto de partida para analisar a arqueologia da psicodinâmica do trabalho no Brasil e sua expansão, enfocando o estado de Goiás.

\section{Método}

Utilizou-se como técnica para a coleta de dados a análise documental. Considerou-se como critério para o levantamento, os laboratórios de pesquisa em Psicodinâmica do Trabalho localizados na região centro-oeste do Brasil que tinham pesquisadores que compunham o Grupo de Trabalho - GT em Psicodinâmica do Trabalho da ANPEPP. A delimitação ocorreu a partir da análise dos dados referentes ao (grupo de pesquisa da Instituição), considerando: sua formação e produção bibliográfica e técnica. Os dados foram submetidos à análise categorial temática. Após a análise temática dos dados relativos à formação e produção bibliográfica e técnica, emergiram duas categorias temáticas que perpassam os trabalhos: a organização do trabalho e a mobilização subjetiva do trabalhador. 


\section{As raízes da psicodinâmica do trabalho no Brasil}

A proposta da abordagem psicodinâmica surgiu como uma possibilidade de preencher uma lacuna ao propor um espaço de discussão sobre as questões ligadas ao trabalho, saúde do trabalhador e sua mobilização subjetiva. Sua visão ampliada, complexa e crítica das relações de trabalho e seu caráter emancipatório contribuíram para que fosse gradativamente adotada em estudos e pesquisas no Brasil, tanto nas universidades quanto em sindicatos que se beneficiaram de projetos de intervenção.

Além dessas características da Psicodinâmica, cabe ressaltar o momento histórico que se vivia no Brasil no que se refere às discussões entre as relações de trabalho e seu impacto na saúde do trabalhador. Por esse motivo, no início, além das relações com as universidades, teve caráter fundamental o suporte dos sindicatos.

Quando questionado sobre os primórdios da Psicodinâmica do trabalho no Brasil, Dejours relembra a primeira visita ao Brasil e os primeiros contatos com pesquisadores brasileiros, que tiveram uma importância fundamental para a introdução da Psicodinâmica no país. (Macêdo \& Heloani, 2017).

Em julho de 1984 houve um seminário franco-brasileiro em São Paulo, que teve na organização Helena Hirata e Anie Thebout (professoras e pesquisadoras da FGV São Paulo). Foi um evento importante que recebeu 20 pesquisadores franceses para discutir diversos temas: ergonomia, economia, sociologia, psicologia, psicopatologia do trabalho, epidemiologia, toxicologia.

Foi a primeira vez que fui ao Brasil. [...] lá conheci vários brasileiros que estiveram ou frequentavam o laboratório de Alain Wisner: Laerte Idal Sznelwar, Neire dos Santos. Pessoas que fizeram a intermediação e que foram muito importantes foram Helena Hirata e Leda Leal Ferreira (p. 497).

No Brasil, a via de inserção prioritária da Psicodinâmica do trabalho ocorreu pelas Universidades (FGV-SP em 1984) e sindicatos. Em diversas regiões do Brasil, em Universidades Públicas, privadas ou confessionais, os pesquisadores que utilizam a PDT o fazem preferencialmente dentro do âmbito de ensino, pesquisa e extensão. Há registros de intervenções realizadas fora da Universidade, porém com pesquisadores ligados a elas, via Fundações e com recursos financeiros advindos de editais de fomento à pesquisa.
Dado seu caráter transdisciplinar, várias ciências utilizam a PDT no Brasil, contudo, a psicologia é a que mais se destaca. A partir de 2001, em decorrência dos pesquisadores brasileiros adotarem a Psicodinâmica do trabalho no campo da produção científica, foram defendidas várias dissertações de mestrado e teses de doutoramento dentro da abordagem da PDT. Assim, em 2007, à medida que os grupos de estudos se expandiam, surgiram os laboratórios de pesquisa específicos da abordagem, associados às universidades em todas as regiões brasileiras e no Distrito Federal. Desde modo, em 2012, foi proposto um Grupo de Trabalho de Psicodinâmica do trabalho no âmbito da Associação Nacional de Pesquisa e Pós-graduação em Psicologia (ANPEPP), cujo principal objetivo é discutir a pesquisa, a política e a formação no âmbito da pós-graduação em Psicologia no Brasil.

A boa aceitação por pesquisadores brasileiros da Psicodinâmica do trabalho fizeram do Brasil, juntamente com o Canadá, os países onde ela floresceu, além da França (Machado \& Macêdo, 2016). Sua divulgação, por meio dos resultados das pesquisas e intervenções, realiza-se em duas frentes de trabalho: pela efetivação de eventos científicos e pela publicação de livros e artigos em periódicos, sendo os dois últimos os mais comuns. Essa tendência dos pesquisadores de concentrar suas publicações em periódicos visa atender a critérios estabelecidos pelas agências de fomento e avaliadoras dos cursos de pós-graduação.

Sobre os eventos, deve-se ressaltar que desde que a Psicodinâmica se inseriu no campo da pesquisa brasileira, os resultados de suas pesquisas foram apresentados em diversos eventos de várias áreas afins. No entanto, a partir de 2007 realizaram-se congressos específicos para essa temática. Em 2007 realizou-se o I Simpósio Brasileiro de psicodinâmica do trabalho, que reuniu, em Brasília, pesquisadores e especialistas na área e que contou a participação de Christophe Dejours durante todo evento (Machado \& Macêdo, 2016). A excelente repercussão fez com que outras edições fossem realizadas, visando divulgar a PDT e possibilitar a formação de redes de pesquisa no Brasil:

- Em 2009, o I Congresso Brasileiro de Psicodinâmica do Trabalho e Clínica do Trabalho e II Simpósio Brasileiro de Psicodinâmica do Trabalho foram realizados em Brasília, promovidos pela Universidade de Brasília e o GT de Psicodinâmica e Clínica do trabalho da Anpepp.

- Em 2010, o I Congresso da Associação Internacional de Psicodinâmica e Psicopatologia 
do trabalho e o VI Colóquio Internacional de Psicodinâmica e Psicopatologia do Trabalho, que foi realizado em São Paulo, com a promoção da referida Associação e da USP.

- Em 2011, o II Congresso Brasileiro de Psicodinâmica do Trabalho e Clínica do Trabalho e III Simpósio Brasileiro de Psicodinâmica do Trabalho foram realizados em Brasília, promovidos pela Universidade de Brasília e o GT de Psicodinâmica e Clínica do trabalho da Anpepp.

- Em 2013, o III Congresso Brasileiro de Psicodinâmica do Trabalho e Clínica do Trabalho e IV Simpósio Brasileiro de Psicodinâmica do Trabalho foram realizados em Gramado- RS, promovido pela UnB e o GT de Psicodinâmica e Clínica do trabalho da Anpepp.

- Em 2015, o IV Congresso Brasileiro de Psicodinâmica do Trabalho e Clínica do Trabalho e V Simpósio Brasileiro de Psicodinâmica do Trabalho foi realizado em Manaus- AM, promovido pela UnB e o GT de Psicodinâmica e Clínica do trabalho da ANPEPP.

- Em 2017, o V Congresso Brasileiro de Psicodinâmica e Clínica do Trabalho (CBPCT) e VI Simpósio Brasileiro de Psicodinâmica do Trabalho, que foi realizado em Brasília/DF.

- Em 2019, o $10^{\circ}$ Colóquio Internacional de Psicodinâmica e Psicopatologia do Trabalho, realizado na Universidade de São Paulo no período de 21 a 23 de agosto e o VI Congresso Brasileiro de Psicodinâmica e Clínica do Trabalho, na Universidade Federal do Maranhão (UFMA), de 19 a 22 de outubro.

Nesses eventos, pode-se observar o crescimento do número de pesquisadores, do número de trabalhos apresentados e do número de participantes, o que indica uma expansão da Psicodinâmica do Trabalho no Brasil. Essa expansão na formação dos pesquisadores resultou em um aumento dos trabalhos realizados não apenas nas universidades, mas também em pesquisas realizadas em outros âmbitos institucionais, como por exemplo: Fundação Oswaldo Cruz-Fio cruz, Petrobras, dentre outras.

Ao lado dos eventos, a divulgação e expansão da PDT por meio de publicações, pode ser evidenciada pelo estudo de Machado e Macêdo (2016) que teve como objetivo levantar o panorama das pesquisas em PDT publicadas no Portal de Periódicos da Coordenação de Aperfeiçoamento de Pessoal de Nível Superior (CAPES)/ Ministério da Educação (MEC), no período entre 2004 a 2014. Como resultado, foram identificados 95 artigos nacionais publicados em português e 50 artigos internacionais, escritos em francês e inglês, por 179 autores, esse dado indica a importância da abordagem no Brasil. Ao analisar as redes de cooperação científica entre instituições e suas respectivas regiões geográficas percebe-se que a região geográfica no Brasil com maior número de cooperações é a região sudeste, possivelmente em decorrência de uma maior concentração de IES na região, conforme pesquisa realizada por Bastos e Gondim (2010).

O estudo realizado por Karam (2012) sinaliza alguns pontos de destaque para o desafio da Psicodinâmica do Trabalho no Brasil. São eles: a construção do espaço de discussão coletiva; levar o trabalhador à aquisição de outra inteligibilidade do sofrimento e do trabalho; trabaIhar com uma clínica que se pauta pela cooperação; a escuta do risco e o compromisso com a verdade e viabilizar a elaboração coletiva das experiências.

Ainda sobre a divulgação e a expansão da PDT, deve-se ressaltara a parceria de Dejours e sua relação com os pesquisadores brasileiros. Sobre esse aspecto, Dejours comenta que: o primeiro é o grupo da USP, que conta com a Selma Lancman, Laerte Idal e Seiji Uchida, desenvolvem várias pesquisas utilizando a psicodinâmica do Trabalho. Em Brasília, atualmente o grupo da Católica de Brasília, com Katia Brasil. Outro grupo importante atualmente para mim é o que desenvolve pesquisa na magistratura brasileira com Leonardo Wandeli, que é juiz, e desenvolve um trabalho importante na área do direito. Tenho outras relações com pesquisadores no Brasil, alguns ligados à Psicanálise e psicossomática. Em Belo Horizonte, Maria Tereza Carvalho Ribeiro, que trabalha com seu marido, Paulo Carvalho em psicanálise e psicossomática no trabalho. No Rio de Janeiro, Marta Rezende Cardoso. Em Porto Alegre, um psicanalista que se chama José Carlos Calich. Em João Pessoa, alguns psicanalistas ligados à Fundação Jean Laplanche, onde eu sou um dos diretores. Em São Paulo Sedes Sapientiae, há um grupo de trabalho nesse instituto, dirigido por Mario Fucks. Há uma formação de psicodinâmica do trabalho lá. Em Goiás, na Pontifícia Universidade Católica de Goiás, a Profa. Dra. Kátia Barbosa Macêdo, que utiliza a Psicodinâmica do trabaIho nas pesquisas e desenvolve parcerias junto ao MPT e ao TRT em Goiás (Macêdo \& Heloani, 2017, p. 499).

Como resultado da expansão da PDT no Brasil, foram fundados alguns laboratórios:

- Em 2003, LIIST - Laboratório de Investigação e Intervenção, ligado ao Departamento de Fisioterapia e terapia ocupacional, da Faculdade 
de medicina USP- Universidade de São Paulo, coordenado pela Profa. Dra. Selma Lancman.

- Em 2004, LSMTEC - O laboratório de Saúde mental, terapêuticas, Educação e cultura da UCB, está ligado ao Programa de Pós-graduação em Psicologia e Educação, da Universidade Católica de Brasília e é coordenado pela Profa. Dra. Kátia T. Brasil.

- Em 2007, LAPCT - Laboratório de Psicodinâmica e clínica do trabalho da UnB, ligado ao Departamento de Psicologia Social e do trabalho, do Instituto de Psicologia da Universidade de Brasília, coordenado pela Profa. Dra. Laboratório foi criado em 2007, pela Professora Ana Magnólia Mendes.

- Em 2007, o GEPOTS - Grupo de Estudos e pesquisas em psicologia, organizações, trabalho e saúde, ligado do Programa Stricto Sensu de Psicologia da Pontifícia Universidade Católica de Goiás coordenado pela Profa. Dra. Kátia Barbosa Macêdo.

- Em 2008, LPDT -Laboratório de Psicodinâmica do Trabalho- UFRGS, ligado ao Programa de Pós-graduação em psicologia social e institucional da Faculdade de Medicina da Universidade Federal do Rio Grande do Sul. Coordenado pelo Prof. Dr. Alvaro Crespo Merlo.

- Em 2010, LAPSIC- Laboratório de Psicodinâmica do trabalho da UFAM, departamento de psicologia da UFAM - Universidade Federal da Amazônia, coordenado pela Profa. Dra. Rosângela Dutra de Moraes.

- Em 2014, LABOR Clínica - Laboratório de Clínica, Saúde e Adoecimento Mental no Trabalho da Tunisinos, Programa de Pós-graduação stricto Sensu de Psicologia da Unisinos- Universidade Vale dos Sinos- RS, coordenado pela Profa. Dra. Janine Kieling Monteiro.

Seguindo a característica do Laboratório do Dejours no CNAM, o caráter transdisciplinar se mantém, sendo que, apesar de predominar a ligação com a psicologia, os laboratórios brasileiros estão sediados em escolas de áreas afins, como medicina. Percebe-se a presença de Laboratórios e grupos de estudos em PDT nas regiões sul, sudeste, norte e centro oeste do Brasil. $\mathrm{Na}$ região centro-oeste, instalaram-se três centros de pesquisa que adotam a PDT como abordagem teórica e metodológica. Destes, dois se localizam no Distrito Federal e um no estado de Goiás. A seguir apresenta-se uma breve descrição destes centros de pesquisa em Psicodinâmica do Trabalho.

\section{LSMTEC- Laboratório de Saúde Mental, Terapêuticas, Educação e Cultura}

O Laboratório de Saúde mental, terapêuticas, Educação e cultura está ligado ao Programa de Pós-graduação em Psicologia e Educação, da Universidade Católica de Brasília foi fundado em 2004 e é coordenado pela Profa. Dra. Kátia Cristina T. Brasil. Uma parte do laboratório está sediada dentro da CAPClinica de Atendimento Psicológico da UCB.

Desenvolve atividades ligadas ao ensino e pesquisa na graduação e pós-graduação dos cursos de psicologia e na área da educação. Realiza alguns cursos de extensão, e também intervenções em órgãos públicos, atendendo a uma demanda que chega à Universidade. Os temas trabalhados abrangem a psicanálise e trabalho, violência e adolescência. (http://www.ucb.br/textos/2/482/ Infraestrutura/?sIT=8)

\section{LAPCT - Laboratório de Psicodinâmica e Clínica do Trabalho da UnB}

O Laboratório foi fundado em 2007, pela Profa. Dra. Ana Magnólia Mendes. Está ligado do Departamento de Psicologia Social e do trabalho, do Instituto de Psicologia da Universidade de Brasília. O objetivo principal das atividades do laboratório é promover o desenvolvimento de pesquisa, formação e práticas profissionais com base em três eixos temáticos: Trabalho, prazer-sofrimento e processo saúde-adoecimento; Práticas em clinica psicodinâmica do trabalho no Brasil e Interfaces em psicodinâmica: organização, trabalho e subjetividade. Com base nesses eixos, os projetos desdobram-se em diversas atividades específicas como pesquisa, orientação de teses, dissertações, especialização e iniciação científica, grupos de estudo e de supervisão, cursos de especialização, estágio em clínica do trabalho, atendimento individual e coletivo em contextos institucionais, clínica escola, sindicatos e organizações, palestras, seminários e colóquios. (www.lpct.com.br).

\section{O GEPOTS - Grupo de Estudos em Psicologia Organi-} zacional, do Trabalho e Saúde

Este laboratório está ligado ao Programa de Pós-Graduação em Psicologia da Pontifícia Universidade Católica de Goiás. Fundado em 2007, é coordenado pela Profa. Dra. Kátia Barbosa Macêdo, utilizando a abordagem da Psicodinâmica do trabalho e investigando 
fatores como organização e condições de trabalho, vivências de prazer e de sofrimento e as estratégias de enfrentamento individuais e coletivas (https://sistemas. pucgoias.edu.br/sigep/espelhoGrupo/show/443).

Vê-se que os três laboratórios estão ligados a Programas de pós-graduação em psicologia. Esse fato impõe aos pesquisadores a necessidade de atendimento às condições colocadas pelas IES e às exigências das agências de fomento e dos periódicos para a publicação das pesquisas.

O LSMTEC e LAPCT situam-se no Distrito Federal, mais especificamente na cidade de Brasília. O GEPOTS Grupo de Estudos em Psicologia das organizações, trabalho e saúde, é o único laboratório situado no estado de Goiás. Apesar da proximidade geográfica, as cidades de Brasília e Goiânia apresentam diferenças importante no que se refere à cultura regional, o que se reflete nas organizações com domicílio nestas cidades. Os dois laboratórios localizados em Brasília, têm em seu entorno a sede do governo federal e as organizações públicas, possuem maior acesso a editais e financiamentos, instalações e gestão institucional que oferecem suporte consistente para a realização e promoção de pesquisa, formação e disseminação do conhecimento.

Já o estado de Goiás, que possui como característica central uma economia embasada na agropecuária, e uma cultura organizacional que apresenta como características uma gestão que privilegia aspectos de autoritarismo, centralização de poder hierárquico e paternalismo constitui um campo desafiador para a implantação da Psicodinâmica do trabalho, exatamente por seu caráter dialógico e proposta de participação e emancipação. (Macêdo, 2002; 2004; Macêdo, Fleury, Lima, \& Carneiro, 2016).

\section{Apresentação dos resultados}

Os resultados relativos ao grupo GEPOTS da Pontifícia Universidade Católica de Goiás serão apresentados considerando os seguintes indicadores: a) formação na graduação e pós-graduação e b) produção bibliográfica e técnica docente e discente.

Os estudos em clinica psicodinâmica do trabalho na Pontifícia Universidade Católica de Goiás se constituem como importante linha de pesquisa e contribui tanto para a formação de profissionais no nível de graduação e pós-graduação, quanto na construção de conhecimento científico, contribuindo para a discussão de questões fundamentais para a sobrevivência dos trabalhadores na sociedade contemporânea.

No período de 2007 a 2019, atendendo ao caráter de formação de pesquisadores, foram concluídas 167 orientações, sendo 23 bolsistas de iniciação científica, 64 trabalhos de conclusão do curso de graduação, 40 trabalhos de especialização Lato Sensu, 27 orientações de Mestrado, 12 orientações de doutorado e uma orientação de pós-doutorado. Estão excluídas desses cálculos as orientações em andamento, que totalizam seis. Delas, dois doutorandos, um mestrando, uma orientação de final de curso de graduação e duas bolsistas de iniciação científica.

Chama a atenção o perfil de seus discentes. Apesar de estarem vinculados a um Programa de Pós-graduação strictu sensu em psicologia, os discentes provêm de cursos de graduação não apenas na área da psicologia, mas também de áreas afins como administração de empresas; serviço social; letras; contabilidade e direito. Fato semelhante ocorre no CNAM, pois Dejours sempre recebeu pesquisadores de várias áreas, enfatizando o caráter multidisciplinar da PDT (Macêdo \& Heloani, 2018).

Outro aspecto que deve ser mencionado é que, de todos os mestrandos que concluíram o curso e não eram professores em Instituições de Ensino Superior, após a conclusão do mestrado, foram aprovados em concursos e seleções, e atualmente atuam no ensino superior. Deles, a maioria ( 23 de 27 discentes) prosseguiu os estudos e concluiu o doutorado, na própria instituição ou em outras. O mesmo ocorreu com os alunos de doutorado, sendo que apenas um ainda não está atuando na docência universitária.

Os cursos onde estão atuando como professores estão distribuídos em várias áreas do conhecimento, como psicologia, administração de empresas, serviço social, letras, contabilidade e direito, tanto em instituições públicas quanto privadas ou comunitárias. Após a titulação, alguns assumiram cargos de coordenação em várias dessas instituições. Indicando uma disseminação da PDT na comunidade em forma de cadeia de conhecimento.

Dentre os projetos desenvolvidos, visando minimizar os danos causados à saúde do trabalhador $\mathrm{e}$ às relações sócio profissionais nas organizações, quatro merecem destaques: 1 - "o trabalho de quem faz arte e diverte os outros"; 2 - "Prevenção do assédio moral e sexual no trabalho"; 3 - "Qualidade de vida no trabalho" 
e 4 - "O trabalho que constitui identidade, inclui e também adoece: saúde mental e trabalho".

No período entre 2007 a 2019, a partir desses projetos, verificam-se 154 publicações, sendo $63 \mathrm{em}$ periódicos nacionais e internacionais; 68 livros e capítulos de livros em coletâneas e 23 artigos em jornais e magazine. Dentre os temas abordados, destacam-se o assédio moral; vivências de prazer e sofrimento advindas das relações de trabalho; prevenção e adoecimento advindo das relações de trabalho.

Para além da importância acadêmica de formação profissional, da produção e da divulgação dos resultados dos estudos em forma de livros e artigos publicados em periódicos científicos ou jornais de notícias, membros do GEPOTS participaram de 254 eventos científicos, palestras e conferências abertas à comunidade e programas de rádio e televisão. Nestas participações, os temas mais explorados foram a prevenção de assédio moral; a gestão de pessoas como fator de promoção de saúde mental do trabalhador; a qualidade de vida no trabalho e a contribuição da psicodinâmica do trabalho.

O GEPOTS teve também a oportunidade de participar da comissão científicas de vários eventos regionais e nacionais, alguns deles ligados diretamente ao Ministério Público, Tribunal Regional do Trabalho, Procuradoria Regional do Trabalho e Sindicatos. Essas atividades tiveram um papel fundamental na sensibilização de promotores, juízes, procuradores e advogados, no sentido de: 1) aderirem à proposta de promoção da saúde mental e prevenção do adoecimento no trabalho; 2) aderirem à implantação de comitês específicos para atendimento a denúncias de assédio moral em organizações. Ações que contribuíram para avaliações melhores fundamentadas de processos na justiça do trabalho.

\section{Análise e discussão}

O que todos esses trabalhos possuem em comum é o fato de adotar a Psicodinâmica do trabalho como base teórica e metodológica, e a partir de suas categorias, ter contribuído para o aprofundamento das relações entre a organização do trabalho e a mobilização subjetiva do trabalhador. A figura 2 demonstra a nuvem de palavras que foi obtida por intermédio da análise computacional (software online tagul) da frequência das palavras utilizadas nos títulos dos artigos, dissertações e teses analisados neste estudo.

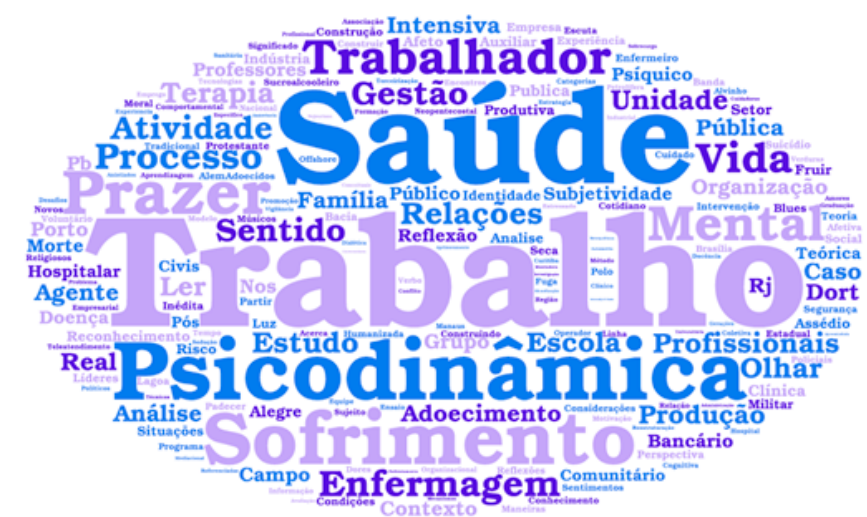

Figura 2. Nuvem de Palavras.

Fonte: Elaborada pelos autores.

Os temas que emergiram com maior frequência foram: o trabalhador (foco principal nas relações entre trabalhador e organização do trabalho), saúde e vivências de sofrimento; seguido pelas vivências de prazer e a gestão. Eles indicam uma convergência com a abordagem Dejouriana. A partir do contexto e da organização do trabalho direciona a escolha do estilo de gestão a ser adotado (Dejours, 2004). E é com base neles que se dá o trabalho prescrito a partir do qual os trabaIhadores se mobilizam subjetivamente. Dependendo dessa mobilização subjetiva, quando há predominância de vivências de prazer ou sofrimento, é que se torna possível transformar o sofrimento em prazer via sublimação, ou em adoecimento. Desse modo, a saúde do trabalhador está intrinsecamente relacionada com a organização do trabalho. Para a Psicodinâmica do trabaIho, o trabalho nunca é neutro. Sempre causa impacto na saúde do trabalhador, a partir da mobilização subjetiva. Como fatores que geram vivências de prazer, foram encontrados: a cooperação; o sentimento de pertença e confiança no grupo; reconhecimento simbólico, que permite desenvolver e fortalecer um sentido positivo em relação ao trabalho e o fortalecimento da identidade; alguns gestores buscam ressignificar seu sofrimento via o reconhecimento de suas equipes; o reconhecimento social permitindo ressignificar o sofrimento e mobiliza os trabalhadores a engajarem-se no desenvolvimento de soluções para os problemas enfrentados em seu contexto de trabalho.

Dentre os fatores que contribuem para as vivências de sofrimento, foram encontrados: um ritmo de trabaIho excessivo; as tarefas são realizadas sob pressão; há rigidez na exigência do cumprimento das normas; muitas vezes há uma defasagem entre a carga de trabalho e o 
número de trabalhadores que compõem a equipe, não havendo quadro de pessoal suficiente para atender à demanda do trabalho, o que indica sobrecarga. Ainda foram encontrados: a falta de flexibilidade; centralização de poder e burocracia; falta de autonomia; pressão por resultados e sobrecarga de trabalho.

Essas condições e relações de trabalho levam o trabalhador a desenvolver estratégias de enfrentamento para lidar com o sofrimento advindo do trabalho, transformando seu funcionamento psíquico, alterando suas formas de existência e incorporando-as não só no trabalho, mas também na sua vida privada e familiar. Dentre as estratégias utilizadas pelos trabalhadores foram identificadas: negação; racionalização; a união/ cooperação e o uso da evasão.

\section{Considerações finais}

O objetivo do texto foi descrever a inserção da Psicodinâmica do trabalho no Brasil e especificamente em Goiás. Evidencia-se sua inserção e expansão ligadas ao contexto da formação de profissionais no nível de graduação e pós-graduação e sua introdução no contexto das organizações que atuam nos três setores de atividade: organizações públicas, privadas e do terceiro setor. Na Pontifícia Universidade Católica de Goiás, ela se desenvolveu por meio de estudos e pesquisas que visaram atuar na prevenção e no tratamento do adoecimento advindo das relações de trabalho, minimizando os danos causados à saúde do trabalhador e às relações nas organizações. Para isso, desenvolveu atividades visando: promover a formação e capacitação de pesquisadores e docentes, desde a iniciação científica até pós-doutores; ampliar o atendimento a trabalhadores e organizações da comunidade, oferecendo serviços de prevenção e tratamento à saúde do trabalhador, cumprindo a função de extensão e comunitária.

Como resultado de sua formação, pode-se afirmar que a inserção da Psicodinâmica do trabalho no Brasil e especificamente em Goiás, manteve uma coerência epistemológica com a proposta de Dejours, servindo como instrumento para a emancipação do trabalhador e a transformação da organização do trabalho.

\section{Referências}

Araújo, T. M., Palma, T. F., \& Araújo, N. C. (2017). Vigilância em saúde mental e trabalho no Brasil: características, dificuldades e desafios. Ciência \& Saúde Coletiva. 22(10), 3235-3246. doi: 10.1590/1413-812320172210.17552017
Bastos, A. V. B., \& Gondim, S. M. G. (2010). O trabalho do psicólogo no Brasil. Porto Alegre: Artmed.

Bendassolli, P.F. \& Soboll, L.A. (2011). Clínicas do trabalho. São Paulo: Atlas.

Dejours, C. (1992). A loucura do trabalho: estudo de psicopatologia do trabalho ( $5^{\mathrm{a}}$ ed. ampliada, A. I. Paraguay \& L. L. Ferreira, Trads.). São Paulo: Cortez Oboré.

Dejours, C. (2004). Subjetividade, trabalho e ação. Production, 14(3), 27-34. doi: 10.1590/S0103-65132004000300004

Houtman, I. L. D., \& Kompier, M. A. J. (2011). Work and mental health Genebra: International Labor Office. Recuperado de https://www. ilo.org/wcmsp5/groups/public/---ed_protect/---protrav/---safework/ documents/instructionalmaterial/wcms_178397.pdf

International Labor Organization. (2000). Mental health in workplace: Introduction. Genebra: International Labor Office. Recuperado de http://www.ilo.org/wcmsp5/groups/public/@ed_emp/@ifp_skills/ documents/publication/wcms_108221.pdf

Karam, H. (2012). Desafio para a psicodinâmica do trabalho no Brasil: um ponto de vista. In A. M. Mendes, Á. R. C. Merlo, C. F. Morrone, \& E. P. Facas (Orgs.), Psicodinâmica e clínica do trabalho: temas, interfaces e casos brasileiros (pp. 53-60). Curitiba: Juruá.

Macêdo, K.B.(2002). Cultura, poder edecisãona organização familiar brasileira. RAE eletrônica, 1, 1-16. doi: 10.1590/S1676-56482002000100014

Macêdo, K. B. (2004). Qualidade de vida no trabalho: o olhar da psicologia e da administração. Goiânia: Editora da Universidade Católica de Goiás.

Macêdo, K. B., Fleury, A. R. D., Lima, J., \& Carneiro, C. M. (2016) A organização do trabalho e adoecimento: uma visão interdisciplinar. Goiânia: Editora da Pontifícia Universidade Católica de Goiás.

Macêdo, K. B., \& Heloani, R. (2017). Introdução e expansão da Psicodinâmica do trabalho no Brasil: entrevista com Dejours. Psicologia em Estudo, 22, 497-502. doi: 10.4025/psicolestud.v22i3.37405

Macêdo, K. B., \& Heloani, R. (2018) A arqueologia da Psicodinâmica do Trabalho no Brasil. Caderno de Psicologia Social do Trabalho. 21(1), 45-59. doi: 10.11606/issn.1981-0490.v21i1p45-59

Machado, L. S., \& Macêdo, K. B. (2016). Análise bibliométrica dos estudos em clinica psicodinâmica do trabalho. Revista Subjetividades, 16(1), 62-76. doi: 10.5020/23590777.16.1.9-22

Molinier, P. (2013). O trabalho e a psique: uma introdução à Psicodinâmica do Trabalho (F. Soudant, Trad.) Brasília: Paralelo 15.

Organisation for Economic Co-operation and Development - OECD. (2012). Sick on the job? Myths and realities about mental health and work. Paris: OECD Publishing. doi: 10.1787/9789264124523-en

Organisation for Economic Co-operation and Development - OECD. (2015). Fit mind, fit job: From evidence to practice in mental health and work. Paris: OECD Publishing. doi: 10.1787/9789264228283-en

Sznelwar, L. I. (2006). Alain Wisner: o desenvolvimento da ergonomia e do pensamento sobre o trabalhador. Travailler, 15, 55-70. doi: 10.3917/trav.015.0055

Uchida, S., Lancman, S., \& Sznelwar, L. I. (2014). Contribuições da Psicodinâmica do Trabalho para o desenvolvimento de ações transformadoras no processo laboral em saúde mental. In D. Glina, R. Miriam, \& L. E. Rocha (Orgs.), Saúde mental no trabalho: da teoria à prática (pp. 191-209). São Paulo: Roca.

World Health Organization. (2000). Mental health and work: Impact, issues and good practice. Genebra:WHO Document Production Services. Recuperado de http://www.who.int/mental_health/media/en/712.pdf 
Psicodinâmica do trabalho: da França ao Estado de Goiás: sua inserção na comunidade

World Health Organization. (2013a). Mental health action plan 2013-2020. Genebra: WHO Document Production Services. Recuperado de http://www.who.int/mental_health/publications/ action_plan/en/
World Health Organization. (2013b). Global plan of action on workers' health (2008-2017): Baseline for implementation. Genebra: WHO Document Production Services. Recuperado de http://www.who.int/ occupational_health/who_workers_health_web.pdf

Kátia Barbosa Macêdo, Doutora em Psicologia Social pela Pontifícia Universidade Católica de São Paulo - PUC São Paulo,

Pós -Doutora em Educação pela Universidade Estadual de Campinas - UNICAMP/Cnam, é Professora Titular da Pontifícia

Universidade Católica de Goiás, PUC-Goiás. Endereço para correspondência: Rua C-181, n. 75, Ed. Hannover, apt 700, Nova Suiça, Goiânia - GO, CEP 74.280-315. Email: katiabarbosamacedo@gmail.com

Fábio Jesus Miranda, Doutor em Psicologia Clínica pela Universidade de Brasília - UNB, é Professor Adjunto da Pontifícia Universidade Católica de Goiás, PUC-Goiás. Email: fabiojmiranda@gmail.com

Recebido em 30.mai.19 Revisado em 07.out.19 Aceito em 31.dez.19 